\title{
"O som que faz a nossa cabeça": relato de engajamento numa experiência pedagógica na aula de portugués do ensino público
}

"Music that Makes up our Minds": interpretive report of engagement in a didactic project in a public school Portuguese class

William Kirsch

Universidade Federal do Rio Grande

Simone Sarmento

Universidade Federal do Rio Grande do Sul

DOI: https://doi.org/10.5902/2176148534852

\begin{abstract}
Resumo: Este artigo apresenta o relato interpretativo da implementação do projeto didático "O som que faz a nossa cabeça" em uma turma de $6^{\circ}$ ano de uma escola estadual de ensino fundamental. o projeto foi baseado nos Referenciais Curriculares de Língua Portuguesa e Literatura do RS e consistiu na produção de um CD da turma, com as canções preferidas dos alunos e notas autobiográficas, relacionando a canção escolhida a aspectos de suas vivências. A análise dos dados qualitativos indica que o projeto foi bem-sucedido, pois revela engajamento por parte dos alunos na execução do projeto tanto dentro como fora de aula.
\end{abstract}

Palavras-chave: Ensino e aprendizagem de língua portuguesa. Sequências didáticas. Gêneros do discurso. Relato de prática pedagógica.

\begin{abstract}
This articleaims at providing an interpretive account of the pedagogical project entitled "O som que faz a nossa cabeça", implemented in a state-school in a metropolitan area of southern Brazil. The project was based on the guidelines proposed by the Rio Grande do Sul State Curriculum. Students produced a class CD in which each student picked a song and wrote an autobiographical essay (published in the CD insert) relating the song to his/her own life experiences. Data analysis (field notes and the collection of students' compositions) indicates student engagement in the activities integral to the project.
\end{abstract}

Key words: Literacy. Writing. Project pedagogy. 


\section{Introdução}

Este artigo retoma essa discussão a partir dos resultados da dissertação de mestrado de Autor (2012) ${ }^{1}$, uma pesquisa que se originou da discussão que prenunciou e procedeu a publicação dos Referenciais Curriculares de Língua Portuguesa e Literatura do Estado do Rio Grande do Sul (Filipouski, Marchi e Simões, 2009; doravante RCLP)². Além disso, esse William trabalho se relaciona com um número de produções posteriores relaKirsch cionadas ao ensino de língua através de projetos.

o projeto didático a ser relatado foi executado na sexta série

Simone

Sarmento

158 de uma escola de ensino fundamental da rede estadual do Rio Grande do Sul em colaboração com a professora regente da disciplina de língua portuguesa. Nele, os participantes elaboraram um CD da turma com um encarte repleto de textos autobiográficos produzidos pelos alunos. Para tanto, os alunos primeiro leram diversos textos, em especial notas autobiográficas, e estudaram esses textos e os recursos linguísticos que os constituíam. Em seguida, cada aluno escolheu uma canção marcante em sua vida e escreveu uma nota autobiográfica explicando o porquê de a canção ser importante em sua história; esses textos, então, foram bilhetados ${ }^{3}$ pela professora e reescritos algumas vezes pelos alunos. Por fim, as canções foram salvas em CD e as notas autobiográficas publicadas no encarte desse CD, que incluiu fotos da turma e um texto de apresentação. Cada aluno, então, ficou com uma cópia do CD, em que se podem ler todos os textos produzidos e ouvir todas as canções a que os textos se referem (disponíveis na íntegra em autor, 2012). Por fim, o CD foi lançado em uma festa junina da escola.

Durante a implementação do projeto, diários de campo (cf. Erickson, 1990) foram gerados, as produções dos alunos coletadas e as etapas do projeto didático registradas fotograficamente. Esses registros constituíram o corpus de que foram cultivados os dados através de leitura, segmentação, análise e catalogação dos conjuntos de ações relevantes para a presente pesquisa (Erickson, 1990; Mason 1996), a saber, aquelas que sugerem: (1) engajamento dos alunos nas atividades do projeto; (2) momentos em que os alunos sustentam publicamente autoria por seus

Este artigo é um apanhado dos capítulos 2, 3 e 4 dessa dissertação.

Cuja proposta será esmiuçada mais adiante.

Entendido aqui como "bilhete orientador da reescrita em atividades pedagógicas escritas realizadas na sala de aula de línguas” (Mangabeira, Costa e Simões, 2011). 
textos, na forma de ações ${ }^{4}$ demonstradoras de preocupação com os efeitos de sentido de seu texto junto ao leitor ou leitora na interação com ele ou ela ${ }^{5}$. Neste artigo, trataremos apenas dos resultados obtidos na análise do primeiro conjunto de interações analisadas.

Focar no engajamento - aqui entendido como participação- dos alunos nas atividades do projeto deriva de nossa adesão à proposição de que participar é aprender e aprender é participar ${ }^{6}$. Dessa forma, aprendemos a participar, participamos e aprendemos, aprendemos para participar e participamos para aprender. Os conceitos de participação e engajamento assim como os de aprendizagem situada (Lave e Wenger, 1991) e comunidades de prática (CoP; Wenger, 1997) serão importantes ${ }^{7}$ nesta análise.

O texto está organizado do seguinte modo: primeiro, fazemos

"O som que faz a nossa cabeça" uma breve revisão teórica dos conceitos fundamentais ao projeto didático executado; depois, apresentamos do cenário de pesquisa e um resumo das tarefas constitutivas do projeto didático aula-a-aula; a seguir, apresentamos dos conjuntos de dados considerados relevantes no corpus; finalmente, tecemos considerações sobre o que os dados têm a dizer ao componente curricular de Língua Portuguesa.

\section{Língua, texto e gêneros do discurso}

Como já indicado na introdução, o projeto pedagógico produzido para os fins desta pesquisa alinha-se com a proposta dos RCLP. Esse documento, produzido pela Secretaria de Educação do Estado do Rio Grande do Sul atualizou e ampliou as reflexões dos Parâmetros Curriculares Nacionais (Brasil, 1997; 1998).

Os PCN apresentam uma estrutura curricular completa, porém flexível, que pode ser utilizada como base para as secretarias estaduais e municipais de educação, ou pelas próprias escolas, na elaboração de seus documentos curriculares. Desse modo, os PCN são o primeiro nível de uma estrutura de concretização em quatro níveis que visam integração e autonomia para toda a rede escolar:

4 Ação entendida como "o ato físico mais a interpretação [acerca do ato físico] sustentada pelo participante e aqueles com quem o participante interage" (ERICKSON, 1991, p. 98).

5 Momentos que ocorreram mormente nas interações entre autores - alunos - e leitores - professo-

ra, pesquisador e colegas - durante as atividades de reescrita.

6 Frase adaptada do trabalho de Schulz (2007).

7 Essa relação será mais explorada na próxima seção. 
1) os PCN, referência brasileira de políticas de currículo do Ministério da Educação, que visam a oferecer subsídios à construção dos currículos dos estaduais e municipais;

2) as propostas curriculares estaduais e municipais;

3) os currículos das escolas, considerando a identidade de seus alunos e demandas locais dos contextos em que estão inseridas;

William

Kirsch

Simone

Sarmento

160

4) o currículo-em-ação, isto é, realizado na sala de aula.

Além disso, os PCN de língua portuguesa são frequentemente considerados uma boa síntese da discussão empreendida no Brasil sobre ensino língua portuguesa na escola - mesmo por seus críticos. $\mathrm{Na}$ introdução ao termo linguagem, o documento argumenta que sua compreensão de tal conceito está ancorada na participação social, na construção de pontos de vista e no compartilhamento da cultura, pois é pela linguagem que o homem interage, acessa informações, expressa pontos de vista, compartilha e desconstrói visões de mundo, etc. (Brasil, 1998, p. 21). o documento afirma que linguagem é

\footnotetext{
ação interindividual orientada por uma finalidade específica, um processo de interlocução que se realiza nas práticas sociais existentes nos diferentes grupos de uma sociedade, nos distintos momentos de sua história. Os homens e as mulheres interagem pela linguagem tanto numa conversa informal, entre amigos, ou na redação de uma carta pessoal, quanto na produção de uma crônica, uma novela, um poema, um relatório profissional. Cada uma dessas práticas se diferencia historicamente e depende das condições da situação comunicativa, nestas incluídas as características sociais dos envolvidos na interlocução (Brasil, 1998, p. 20).
}

Poderíamos resumir essa concepção do seguinte modo: (1) linguagem é interação (ação interindividual), e ancora-se tanto em elementos contingentes (quem fala/escreve com/para quem e qual a relação entre ambos) quanto mais amplos da situação de produção do discurso (assunto, registro, momento histórico, etc.); (2) os sujeitos interagem através de gêneros escritos ou orais historicamente construídos (e-mail, crônica, entrevista, conversa cotidiana); (3) esses gêneros são diferentes nas distintas situações de produção do discurso. Portanto, produzir 
linguagem significa produzir discursos, isto é, significa dizer alguma coisa para alguém, de uma determinada forma, num determinado contexto histórico. Isso significa que as escolhas feitas ao dizer, ao produzir um discurso, não são aleatórias - ainda que possam ser inconscientes -, mas decorrentes das condições em que esse discurso é realizado. (Brasil, 1998, p. 22).

O discurso, desse modo, se materializa em textos orais e escri$\operatorname{tos}^{32}$. Esses textos se organizam através gêneros, isto é, formas relativamente estáveis de enunciados disponíveis na cultura, caracterizados por conteúdo temático, estilo e construção composicional (Brasil, 1998, p. 23), e se relacionam com outros textos já produzidos.

É ao segundo nível de elaboração curricular mencionado acimaque os RCLP correspondem. OS RCLP propõem uma estrutura curricular completa para todos os anos do ensino básico ${ }^{8}$. O documento de - Linguagem, Códigos e suas Tecnologias define que a área

\begin{abstract}
trata o conceito central de linguagem como a capacidade humana de articular significados coletivos em códigos, ou seja, em sistemas arbitrários de representação, compartilhados e variáveis, e de lançar mão desses códigos como recursos para produzir e compartilhar sentidos. Isso quer dizer que a cada linguagem correspondem códigos específicos, mais estáveis, mas que acima de tudo a linguagem se atualiza na prática, é historicamente construída e dinâmica. Através dela, os sujeitos agem no mundo social, participam em interações com o outro nas situações que encontram em sua vida cotidiana. Pelo uso da linguagem, o ser humano se torna capaz de conhecer a si mesmo, sua cultura e o mundo em que vive. (Rio Grande do Sul, 2009, p. 37).
\end{abstract}

O segmento acima tem algumas similaridades com os PCN (especialmente Brasil, 1998): (1) a linguagem é entendida como interação; (2) que se dá através de formas historicamente construídas e dinâmicas;

8 O documento apresenta um conjunto de temáticas e gêneros do discurso para todos os anos do ensino básico, bem como exemplos de como esses temas e gêneros podem ser convertidos em projetos para o ensino de português levando em conta a série, idade e desenvolvimento sociognitivo dos alunos. A partir disso, as escolas e docentes podem formular projetos relevantes tanto para a comunidade escolar como para as turmas em questão. 
(3) pela linguagem os sujeitos conhecem a si próprios e constroem suas visões de mundo. No campo da disciplina de Língua Portuguesa e Literatura, o documento anota que a

William

Kirsch

Simone

Sarmento

162

cada língua corresponde a um sistema estruturado, mais estável, mas que acima de tudo se define como trabalho interacional situado, atualizado na prática, historicamente construído e dinâmico. Através da língua (materna ou outras), os sujeitos agem no mundo social, participam em interações com o outro nos mais variados contextos. Mergulhados no uso de sua língua (ou de outras), os sujeitos constituem a si mesmos, constroem conjuntamente uma compreensão do mundo e, ao mesmo tempo, reconstroem continuamente a própria língua. Enfim, ao privilegiar a língua portuguesa e a literatura, a disciplina tem, necessariamente, como objeto, o uso da linguagem, pois é na constante construção da vida social viabilizada por tal uso que o ser humano se torna capaz de conhecer a si mesmo, sua cultura e o mundo em que vive (Rio Grande do Sul, 2009, p. 55).

Ao ancorar o trabalho disciplinar no texto, assim como faz Brasil (1998), os RCLP assinalam que o texto, como unidade mínima de uso da língua na interação, o deve ser a base da aula de língua portuguesa. Além disso, tanto os PCN como os RCLP se valem do conceito de gênero do discurso como uma figura intermediária entre o caos das situações de produção do discurso e os repertórios histórico e culturalmente estabelecidos de tipos relativamente estáveis de textos que ajudam a mediar esse caos nas instâncias de uso da língua.

Como o projeto didático utilizado para esta pesquisa se alinha com a proposta dos RCLP, tem um universo conceitual semelhante. Ou seja, aqui língua pode ser entendida como interação situada por meio de códigos socialmente construídos e dinâmicos através dos quais construímos e compartilhamos nossa cultura, bem como nossas visões de mundo. Nossas interações, dessa forma, se materializam em textos, que, nas práticas discursivas, estruturam-se e organizam-se em gêneros do discurso, isto é, estruturas relativamente estáveis que respondem ao contexto de produção dos textos e organizam os usos da língua (Filipouski, Marchi e Simões, 2009).

LetRAS, Santa Maria, v. 29, n. 58, p. 157-181,jan./jun. 2019 
Ao situar-se nesse enquadre, os RCLP assinalam que a aula de língua portuguesa e literatura deve inevitavelmente centrar-se no uso da língua, e, por conseguinte, no texto. Portanto, ao produzir um projeto didático comprometido com o marco teórico discutido acima, é essencial que as dimensões sociais e interacionais de que as interlocuções emergem, e partir das quais são ajustadas, sejam tratadas como o epicentro pedagógico das atividades de leitura, estudo do texto e produção textual, na medida em que não há leitura, estudo do texto ou de linguagem, e produção textual pertinente e significativa sem que essas relações estejam sempre dentro do radar. Além da centralidade da leitura, produção de textos e publicação dos mesmos, o investimento em suportes que potencializem as oportunidades de os textos circularem junto a interlocutores concretos, dentro

"O som que faz a nossa cabeça" e fora da sala de aula e da escola, pode incentivar o aluno a tornar-se autor de seus textos, no sentido de assumir-se como responsável pelos efeitos de sentido que seus textos produzam nos interlocutores endereçados. É no campo do como articular esse marco teórico na forma de proposta de ensino que o conceito de projeto didático vem à tona. Passemos, então, a esta discussão.

\section{Ensino e aprendizagem por projetos na aula de língua portuguesa}

No campo do ensino de língua portuguesa, o conceito de projetos para ensino e aprendizagem não é novo. Há mais de três décadas, Geraldi (1984, p. 57-62) já apontava o uso de projetos de classe como uma possível forma de se instaurar situações concretas que possibilitem interlocuções efetivas por meio de leitura e produção de textos, a serem disponibilizados para um público mais amplo de leitores. Essa proposta responde diretamente à demanda de se fazer um trabalho escolar centrado em leitura e produção textual que transcenda à escrita mecânica para o professor ler, avaliar e corrigir, pois afirma que a produção de textos deve: (1) ser orientada a leitores concretos, a partir de algo que se tenha a dizer e que se queira dizer, (2) ter um locutor que se constitua como tal na linguagem como alguém que diz o que diz para quem diz; (3) ter um conjunto de recursos e estratégias para se realizar 1 e 2 (Geraldi, 1997, p. 137). Ou seja, os projetos de classe devem culminar em coletâneas públicas de textos. 
Posteriormente, os PCN definem projetos do seguinte modo:

um projeto [...] tem o objetivo compartilhado por todos os envolvidos, que se expressa num produto final em função do qual todos trabalham... Os projetos são situações em que linguagem oral, linguagem escrita, leitura e produção de textos se inter-

William

Kirsch

Simone

Sarmento

164 -relacionam de forma contextualizada, pois quase sempre envolvem tarefas que articulam esses diferentes conteúdos. São situações linguisticamente significativas, em que faz sentido, por exemplo, ler para escrever, escrever para ler, ler para decorar, escrever para não esquecer, ler em voz alta em um tom adequado... (Brasil, 1998, p. 47-8).

Nos RCLP, os projetos didáticos ganham uma posição de destaque que não têm no documento nacional - onde aparecem apenas como uma “organização curricular especial" (Brasil, p. 87) -, pois a diretriz curricular do Rio Grande do Sul propõe que o currículo todo seja baseado na seleção de projetos a serem executados durante o ano letivo. Ou seja, para os RCLP os projetos didáticos constituem as unidades básicas do currículo no plano da organização dos conteúdos, afirmando o seguinte:

não é possível ensinar a produzir textos apenas exigindo que os alunos preencham páginas que serão corrigidas, não havendo jamais uma leitura significativa daquilo que produziram. Por isso, nestes Referenciais, não se considera o ciclo da produção textual terminado se não houver leitura significativa do texto dos alunos. Nos quadros de progressão curricular apresentados ao final deste Referencial (p. 173), vários projetos são sugeridos para que, em cada etapa da educação básica, as tarefas de leitura e produção de textos convirjam para um produto público, que terá leitores concretos e interessados. (Filipouski, Marchi e Simões, 2009, p. 67).

Desse modo, os RCLP propõem que o trabalho escolar da aula de língua - portuguesa e adicional - seja pautado em projetos, escolhidos a partir do quadro oferecido aos docentes pelo próprio documento ou formulados na íntegra pelos professores (com os alunos), organizados em unidades didáticas moduladas, que incluam tarefas de leitura, compreensão e estudo 
do texto; tarefas de estudo de recursos linguísticos pertinentes para a escrita de textos do gênero em questão; tarefas de escrita, revisão dos textos em pares e pelo professor, bem como atividades de reescrita; e, muito importante, um momento em que os textos sejam "publicados" (no sentido de disponibilizados) para leitores concretos, isto é, para além do professor - muitas vezes o único leitor dos textos dos alunos.

Nesta concepção, os projetos são estruturados a partir da articulação de duas questões: temas que sejam pertinentes à vida dos alunos e gêneros do discurso que (cor)respondam a esses temas. Esses pontos são convergentes nas práticas de linguagem porque a relação entre temáticas e gêneros do discurso é orgânica, isto é, a cada universo temático corresponde um repertório de gêneros pelos quais os temas são dizíveis (Bakhtin, 2010).

"O som que faz a nossa cabeça"

Essa concepção de projeto pode ser resumida assim: (1) o estabelecimento (em conjunto com os alunos) de uma temática e de um produto final (uma coletânea pública de textos), a ser produzido no fim do trabalho; (2) a escrita de um texto inicial, cuja finalidade é investigar os recursos expressivos que os alunos precisam aprender para produzir o texto do projeto adequadamente; além de servirem como referência para a avaliação final dos textos dos alunos; (3) aulas de leitura, compreensão e estudo de textos de referência; (4) aulas de estudo dos recursos linguísticos pertinentes ao gênero da produção final, sobretudo aqueles que os alunos apresentaram dificuldades na produção inicial; (5) momentos destacados ao planejamento de como se produzir e publicar a coletânea de textos do projeto; (6) aulas de escrita, edição e reescrita dos textos do projeto; (7) um momento de publicação do texto para seus leitores concretos, dentro e fora da sala de aula.

\section{Escrita na sala de aula de Língua Portuguesa}

O trabalho com a escrita de textos em sala de aula tem sido objeto de muitos estudos, haja vista o grande número de pesquisas e publicações existentes sobre o assunto (Geraldi, 1997; Brasil, 1998; Filipouski, Marchi e Simões, 2009; Rodrigues, 2007; Autor, 2012). Todos os estudos citados têm em comum um alinhamento com a perspectiva de linguagem como discurso delineada acima. Nesse sentido, esses estudos propõe um avanço no sentido no que a tradição convencionou chamar de "redação" em prol do que, contemporaneamente, vimos chamando "produção textual" (Rodrigues, 2007, p.1). Tal mudança estabelece como pre- 
missa para a execução do trabalho com a escrita de texto em sala de aula, que se criem às condições de produção textual. Por isso, a opção pelo termo produção textual implica na assunção de um paradigma em que escrever é interagir com outro(s) por meio da escrita.

No campo da prática de ensino de língua portuguesa na escola, tem-se produzido em nosso meio propostas pedagógicas ancoradas nos

William gêneros textuais (Schnewly e Dolz, 2004). Nessas propostas muito difun-

Kirsch didas entre nós nas últimas duas décadas, o ensino de escrita preconiza o ensino de textos a partir da leitura e estudo de textos de um gênero Simone base, com foco, sobretudo, nos aspectos sociorretórico e formais dos gêSarmento neros textuais, a partir de projetos de classe. Há críticas (Autor, 2012) de que tal forma de encarar a escrita como reprodução formal das características dos gêneros de discurso seja uma espécie de volta da gramática pela porta dos fundos. De modo distinto, há uma série de trabalhos que se valem do conceito de gênero do discurso para ancorar a reflexão pedagógica de projetos didáticos (ou projetos de trabalho) ancorados na produção de discursos; tais projetos têm por premissa que os textos produzidos pelos alunos devem ser organizados em coletâneas públicas de textos a serem endereçados a interlocutores concretos dentro e fora da sala de aula (Geraldi, 1997; Filipouski, Marchi e Simões, 2009; Simões et al, 2012; Almeida e Corrêa, 2017), muitas vezes sem menção a um gênero do discurso reconhecível nas práticas sociais (como carta ao leitor, lista de compra, ensaio, etc.) ou com um gênero do discurso emergente de um pacto pedagógico entre professor e aluno. Nesse sentido, considera-se que essa seja uma perspectiva mais alinhada à escrita como produção, em vez de reprodução.

\section{Escola Estadual de Ensino Fundamental Santo Anselmo: cenário de pesquisa}

A pesquisa foi executada na Escola Santo Anselmo (pseudônimo, como todos os demais nomes próprios utilizados), situada na região central de uma grande cidade do Rio Grande do Sul. A escola é considerada pelas professoras uma escola "de inclusão" (termo delas) porque parte considerável de seus alunos vem de áreas pobres, abrigos ou têm necessidades especiais e não se adaptam em outras escolas da rede estadual - seja por risco social ou por algum transtorno, síndrome ou dificuldade cognitiva. A Santo Anselmo os acolhe em turmas do primeiro ao nono ano do ensino fundamental (uma por ano); duas turmas de ensino de 
jovens e adultos, sendo uma de alfabetização (equivalente ao primeiro e segundo anos) e outra para alunos já alfabetizados (terceiro e quarto anos); e uma turma de TGD (transtornos globais de desenvolvimento) com alunos com diversos transtornos. Ao todo são 250 alunos atendidos em dois turnos - manhã e tarde - por 20 professoras e sete funcionárias (duas secretárias, dois auxiliares de serviços gerais e três merendeiras) ${ }^{9}$.

\section{Projeto "O Som que faz a Nossa Cabeça"}

Como já explicitado na introdução, o projeto constituiu-se da produção de um CD da turma articulando canção e nota autobiográfica ${ }^{10}$. 0 conjunto de aulas teve por meta que, ao fim e ao cabo, os alunos conseguissem: (1) ler notas autobiográficas que tecessem relações entre as experiências de vida do autor e a construção de seu gosto musical; (2)

"O som que faz a nossa cabeça" compreender as relações entre experiências de vida e o gosto de cada um; (3) compreender os gostos alheios, sobretudos os diferentes dos seus, como manifestações das vivências de cada um; (4) escrever notas autobiográficas construindo relações entre suas vivências e a canção escolhida para o projeto. 0 quadro sinóptico abaixo apresenta um resumo das tarefas do projeto aula a aula.

\begin{tabular}{|c|c|}
\hline Data & Aula \\
\hline $14 / 06 / 2011$ & - Apresentação dos termos "gênero musical" e "canção" \\
\hline $15 / 06 / 2011$ & - Discussão e escuta "Meus Amigos", de Emicida \\
\hline $16 / 06 / 2011$ & - Estudo do texto canção "Meus Amigos" \\
\hline $21 / 06 / 2011$ & - $\quad$ Roda de Música \\
\hline $28 / 06 / 2011$ & - $\quad$ Roda de música parte 2 \\
\hline $29 / 06 / 2011$ & - $\quad$ Leitura nota biográfica de Raul Seixas \\
\hline $30 / 06 / 2011$ & $\begin{array}{ll}\text { - } & \text { Leitura nota autobiográfica Raul Seixas } \\
\text { - } & \text { Estudo tempo pretérito imperfeito/perfeito }\end{array}$ \\
\hline $05 / 07 / 2011$ & - Aula sobre antologias na biblioteca \\
\hline $06 / 07 / 2011$ & - Discussão sobre o projeto e escrita texto diagnóstico \\
\hline $12 / 07 / 2011$ & - Torneio de Futebol contra o colégio Britânico \\
\hline $13 / 07 / 2011$ & - Leitura nota biográfica Nelson Motta \\
\hline $14 / 07 / 2011$ & - Escolha dos livros para leitura nas férias \\
\hline
\end{tabular}

9 Dados atualizados em 26/10/2011 com a direção da escola, à época da redação do relatório final de pesquisa de mestrado.

10 Por uma questão de economia, em vez de explicitar novamente o projeto, arremeto o leitor novamente à introdução. 
William

Kirsch

Simone

Sarmento

168

\begin{tabular}{|l|cl|}
\hline Férias & \multicolumn{2}{|l|}{ 2 Semanas } \\
\hline $02 / 08 / 2011$ & $\cdot$ & Conversa sobre os livros lidos \\
\hline $03 / 08 / 2011$ & $\cdot$ & Leitura da Nota autobiográfica de Nelson Motta \\
\hline $04 / 08 / 2011$ & $\cdot$ & Leitura da Nota autobiográfica de Nelson Motta \\
\hline $09 / 08 / 2011$ & $\cdot$ & Texto sobre Forró \\
\hline $11 / 08 / 2011$ & $\cdot$ & Estudo da pontuação e escrita da nota autobiográfica \\
\hline $16 / 08 / 2011$ & $\cdot$ & Revisão dos textos bilhetados em papel \\
\hline $17 / 08 / 2011$ & $\cdot$ & Revisão dos Textos no Computador \\
\hline $23 / 08 / 2011$ & $\cdot$ & Revisão dos Textos no Computador \\
\hline $24 / 08 / 2011$ & $\cdot$ & Revisão dos Textos no Computador \\
\hline $25 / 08 / 2011$ & $\cdot$ & Festa de despedida e lançamento do CD \\
\hline
\end{tabular}

Quadro 1: resumo do projeto aula a aula/class project synopsis

Fonte: Autor (2012, p. 80-82)/ Source: Author (2012, p. 80-82)

\section{Pensando o projeto a partir do engajamento}

A partir da adoção de um ponto de vista acerca do que constitui aprendizagem, pode-se pensar nos índices que irão indicar aos observadores - professor ou pesquisador - o sucesso pedagógico. Isso serve tanto para a avaliação do projeto como um todo quanto para a avaliação formativa e somativa dos indivíduos. Diferentemente de um paradigma em que as aprendizagens sejam delimitadas a partir do número de questões de uma prova, ou na semelhança do texto dos alunos com os textos base, aqui vemos a participação nas diversas atividades que constituem o projeto como lócus onde a aprendizagem pode ser observada.

Como dito anteriormente, parte-se nesta pesquisa do pressuposto de que participar é aprender e aprender é participar. Mais especificamente, adotamos o conceito de aprendizagem situada (Lave e Wenger, $1991)^{11}$. Em sua pesquisa seminal, os autores propõem “ a aprendizagem vista como atividade situada [tendo] como sua característica definitiva um processo chamado de participação periférica legítima" (p. 29) ${ }^{12}$. Participação periférica legítima relaciona-se com o processo por meio do qual os novatos em uma comunidade de prática a ela se integram, visto que, para os autores, aprendizagem é o processo de tornar-se um participante pleno em uma prática ou comunidade. Esse processo pressupõe

11 Situated Learning. Tradução nossa, como todas doravante, salvo menção contrária.

12 Learning viewed as situated activity has as its central defining characteristic a process that we call legitimate peripheral participation. 
aprendizagem. Desse modo, aprendizagem situada é o modelo analítico criado pelos autores para dar conta de situações de aprendizagem onde a participação e a mudança de status dos sujeitos são visíveis - como no caso do apprenticeship (e.g parteiras, alfaiates, açougueiros, alcoólicos anônimos e contramestres navais) ${ }^{13}$. Segundo os autores, então, a aprendizagem decorre da participação dos sujeitos em comunidade de prática, e é visível pela transformação nos modos de participação dos sujeitos - de periféricos para plenos. Desse modo, aprender é apoderar-se dos modos de participar, das práticas e dos modos de fazer sentido de uma dada comunidade.

Nesse sentido, um projeto de classe como o proposto aqui implica a construção de uma comunidade capaz de lidar com a empreitada em mãos, isto é, a finalidade que dá coesão à comunidade prática como

"O som que faz a nossa cabeça" algo para além de um coletivo de pessoas unidas no espaço-tempo. Em outras palavras, uma comunidade de prática necessariamente está unida em torno de uma finalidade principal, que, neste caso, é o projeto didático da construção do $\mathrm{CD}$ da turma. Por isso, construir um sentido de comunidade a partir do trabalho e de um projeto comum foi essencial no percurso dessa intervenção pedagógica.

Desse modo, torna-se evidente que o foco dessa intervenção pedagógica foi o engajamento nas diferentes atividades que compuseram o projeto. Por isso, o foco principal da pesquisa foi a ação social dos sujeitos durante o período de trabalho do projeto. Entretanto, como ensina Erickson (1990), para analisarmos ação social, o único caminho possível é observarmos os comportamentos dos sujeitos e tentarmos inferir suas aparentes interpretações dos significados desses comportamentos.

Ao relermos o corpus de dados, atentamos às seguintes perguntas: (1) o produto final esperado foi produzido adequadamente?; (2) quais formas de engajamento nas atividades de sala de aula sugerem o sucesso da empreitada?; (3) quais práticas estão relacionadas a propiciar aos alunos acesso à escrita e aos discursos letrados ${ }^{14}$ ?

Nesta seção, apresentaremos alguns dados que sustentam a asserção acima. Para tanto, usaremos as perguntas como guia.

13 Entendido como um modelo de aprendizagem onde um aprendiz convive com um profissional experiente e vai, no contato com ele ou ela, aprendendo um certo quefazer, normalmente um ofício. 14 Inspirado em Britto (1997 apud 2007). 


\section{0 produto final esperado foi produzido adequadamente?}

$\mathrm{O} C \mathrm{C}$ foi o ponto de partida e de chegada do projeto porque constituiu o suporte em que os textos dos alunos foram tornados públicos para leitores concretos; o objetivo principal do trabalho, aquilo para que todas as tarefas convergiam. A ideia do CD foi discutida logo no princípio da sequência

William de aulas e os alunos foram consultados sobre sua disponibilidade para o Kirsch produzirem. Como a maioria dos alunos demonstrou interesse em fazer o CD, passamos a um planejamento de como organizar nosso tempo, pois Simone produzi-lo implicava uma série de demandas - escolher as músicas, levanSarmento tar o dinheiro, fazer o download das músicas, comprar os insumos (CDs virgens, caixinhas de $\mathrm{CD}$, papel), escrever os textos, reescrever os textos, 170 editar o material, fazer as impressões, tirar uma foto da turma e montar os CDs, além, evidentemente, das tarefas pedagógicas de leitura, estudo do texto e de recursos linguísticos identificados como lacunares a partir dos textos iniciais dos estudantes. Assim, fizemos - a professora regente da turma e eu ${ }^{15}$, pesquisador - um plano de ação em que as tarefas foram compartilhadas entre todos: nós e os alunos, o qual compartilhamos em aula e solicitamos voluntários para desenvolver as tarefas. Os alunos pesquisaram o preço dos insumos em vários locais e fizeram uma lista de canções (uma escolhida por cada um), e alguns se responsabilizaram pelo download das canções e pela gravação dos CDs. Além disso, eles arrecadaram parte dos fundos para o $\mathrm{CD}$, vendendo algumas cópias para pais e professores. A mim competiu fazer a edição dos textos já prontos e digitados, e sua impressão, sendo que os alunos recortaram e fizeram a montagem dos CDs.

O CD consiste em: capa com a foto da turma, contracapa com os nomes de todas as canções e alunos que as escolheram, encarte com os 23 textos dos alunos que permaneceram na escola até o fim do projeto, e o CD gravado com todas as canções escolhidas pelos alunos. Todas as etapas do CD foram realizadas pelos alunos, tanto em sala de aula (escrita, reescrita e digitação dos textos; diagramação dos textos; foto e diagramação da capa; recorte e montagem dos CDs) como fora (compra das mídias para os CDs; download e gravação das canções nas mídias; impressão das capas e textos no laboratório da escola ${ }^{16}$ ). Além disso, todos os alunos frequentes escreveram e reescreveram seus textos, pau-

15 Será utilizada a primeira pessoa do singular quando nos referirmos à elaboração e condução das aulas por um dos autores deste texto.

16 Apenas alunos voluntários, fora do horário das aulas. 
tados pelos bilhetes produzidos pela professora e pelo pesquisador, bem como por sugestões de colegas e de outros amigos que leram os textos em seu processo de escrita. Por uma questão de espaço, infelizmente é impossível reproduzir o todo do encarte neste texto.

\section{Quais formas de engajamento nas atividades de sala de aula sugerem o sucesso da empreitada?}

Ao relermos os dados, verificamos que há dois possíveis olhares para o engajamento: (1) da comunidade como um todo (atividades com mais ou menos engajamento), e (2) a trajetória de alunos específicos, focando especialmente na mudança em sua participação. Ambos os olhares apresentam aspectos interessantes do projeto.

Há, nos diários de campo, um número relevante de descrições de

"O som que faz a nossa cabeça" ações alinhadas ao projeto, tanto dentro como fora de sala de aula, cuja frequência parece ter progredido num eixo temporal. Ao reler todas as 22 entradas no diário de campo, encontra-se mais de 80 momentos em que a narrativa assinala que os alunos estão demonstrando engajamento nas atividades pedagógicas, por meio de uma gama de ações demonstradoras desse engajamento ${ }^{17}$. Para este texto, foram escolhidos dois excertos de diário de campo considerados típicos, na medida em que são semelhantes a tantos outros registrados (nos índices destacados dos dados e na interpretação destes), porém mais fáceis de serem entendidos fora do todo da narrativa dos diários.

O primeiro excerto escolhido para ser apresentado é de uma das primeiras aulas. Foi solicitado que cada aluno tocasse para toda a turma um trecho da música escolhida para o projeto e explicar para os colegas o motivo de tê-la escolhido, explicando o porquê de a canção ser importante para sua história de vida.

Excerto 1: Aula 4 e 5 - Roda de Música I \& II (21/06/2011 e 28/06/2011) - Um fala, outro escuta, outro dança, outro canta... Deixei de antemão a sala de informática pronta para a aula: dois alto-falantes potentes ligados num computador com o site youtube.com aberto. Os alunos sentam-se em círculo e são orientados por Sandra, a professora, a não ligarem os computadores,

17 Pesquisar o preço de insumos; discutir o projeto no meio de um torneio de futebol; pesquisar preço de insumos no contraturno da aula; trazer a letra de sua canção escolhida impressa ou manuscrita para a aula; realizar atividades de leitura e compreensão do texto; escrever e reescrever textos; solicitar ajuda na escrita e reescrita de seus textos; entre outras. 
pois precisam ouvir os colegas - suas canções e explicações. São orientados por Sandra a fazerem silêncio e a anotarem as canções escolhidas pelos colegas nos cadernos de atividades, bem como a não debocharem das escolhas dos colegas. Eu sou o primeiro a falar da minha canção: "Naquela Mesa”, cantada por Nelson Gonçalves, pois me lembra muito do meu avô.

William

Kirsch

Simone

Sarmento

172

Em seguida Michel, sentado à frente do círculo, pede sua música: "História de um Guerreiro", do Mc Duduzinho. Ele fica olhando para os colegas, que já se cutucam e riem, e diz: -“Ô sangue! Não é contigo que eu estou falando. É minha música e tu não tem nada que ficar rindo". E segue, olhando para mim nos olhos: "Esta música conta a história de muita gente pobre, que nem eu, que sofre preconceito e que as pessoas não entendem, ficam implicando, por isso eu me identifico com ela". Fico bastante espantado com a seriedade dele, pois ele é tido como um dos maiores "problemas disciplinares" da turma. Nessa aula, ele ficou quieto, pediu silêncio, falou sobre suas preferências e não teve o nome mencionado por Sandra uma vez sequer. [...] Ao fim da aula não foi possível que todos os alunos falassem de suas canções e decidimos deixar para a próxima aula. Uma grata surpresa: Sofia e Pedro, que disseram primeiramente que não iam falar nada, ficaram no início da lista para a aula seguinte. (Diário de Campo, 21/06/2011).

Nessa aula, segundo aponta a narrativa do diário, a maioria dos alunos esteve engajada na atividade pedagógica: falando sobre sua música, ouvindo a música do colega ou sua justificativa por tê-la escolhido. Os momentos de participação exuberante (cf. Rampton, 2006) ${ }^{18}$ - dança, cantoria, imitações - podem ser interpretados como engajamento na atividade pedagógica em curso, e demonstram publicamente o alinhamento com a atividade sendo executada pelo grupo. Cumpre destacar a participação de Wellington, tido como um dos alunos mais indisciplinados na turma, que não apenas demonstrou seriedade na hora de falar de sua canção, e endereçou a tarefa de aula de forma plenamente satisfatória na avaliação da professora

18 Como explica Lange (2010), apesar de os alunos não estarem seguindo a ordem canônica e, frequentemente, estarem fazendo "participações exuberantes" (participando de forma não muito convencional: cantando, chamando atenção ou debochando de alguma coisa que ocorreu na aula) eles estão, de algum modo, engajados no que está acontecendo dentro do espaço aula e estão contribuindo para o andamento da atividade. Desse modo, resistir à estrutura convencional de participação não é equivalente a resistência à participação. 
Além desse, há o caso dos alunos Pedro e Sofia, que no início do encontro apresentaram resistência a mostrarem sua canção e explicar para a turma o porquê de as terem escolhido, mas, no fim deste encontro, se voluntariaram para serem os primeiros a falar no encontro seguinte, e o fizeram. Esse momento no excerto sugere a mudança de posição de dois alunos, de uma posição resistente ao engajamento para uma posição alinhada ao engajamento. A leitura do excerto, em sua totalidade, sugere a participação dos alunos, que, em sua maioria, conseguiram explicar os motivos pelos quais as músicas que escolheram serem tão importantes para sua vida, valendo-se de elementos concretos de suas vivências.

Já próximo ao fim do projeto, especificamente no dia 17/08/11, o excerto abaixo mostra a narrativa de uma interação entre uma aluna e o pesquisador. Neste encontro, os alunos receberam os textos bilhetados

"O som que faz a nossa cabeça" pela professora e pelo pesquisador, e tinham um período para, em pares e com o auxílio de dicionários, reescrever seus textos. Em nove momentos registrados em diário de campo, diferentes alunos principiaram em uma discussão acerca dos bilhetes escritos a respeito de seus textos. 0 excerto abaixo descreve um desses momentos, em que uma aluna veio discutir o bilhete e as possibilidades de revisão de seu texto comigo.

Excerto 3: Já descobri como explicar porque acho a música linda! (17/08/2011)

Estamos na sala de informática para que os alunos reescrevam a segunda versão de seus textos. Os alunos estão sentados em frente aos computadores em duplas, com a primeira versão de seu texto já lida e bilhetada por mim. A maioria dos alunos reescreve seus textos com música tocando baixinho em seus celulares, porém alguns olham seus perfis no site Orkut.com. Sandra está sentada com dois alunos que não fizeram as primeiras versões do texto [um era recém chegado à escola e outro ficara dois meses sumido do abrigo]. Sofia me chama para perto de seu computador, "Nome do autor!" acenando com a mão levantada. Chego a seu lado e Sofia me olha nos olhos com seus olhos muito pretos, aponta para seu texto e pergunta: "Por que tu quer saber por que eu acho a música linda?”. Eu respondo: “Tu não acha que, se a proposta do texto é explicar porque a música que tu escolheu é importante para ti, não cabe que tu explique que relação tu tem com esta música?". Sofia me olha com a testa franzida, segurando seu co- 
elho de pelúcia e diz "sim". Ela acrescenta: “Tá [...]. Vou pensar um pouco." Mais da metade de sua reescrita já está feita.

Fico de longe, da mesa do professor, observando Sofia. Ela olha a folha. Joga-a contra a mesa e diz para Giovani que não vai escrever mais. Em alguns segundos, pega a folha novamente e olha-a fixamente. Joga-a de novo contra a mesa do computador. Ao cabo de

William

Kirsch

Simone

Sarmento

174

aproximadamente cinco minutos ela me chama, com um sorriso encantador, mostrando os dentes brancos e perfeitos na pele cor de mogno, e diz: "Já sei como eu vou explicar! Tá, tá, depois eu te chamo!”. Dentro de alguns minutos, Sofia me chama e mostra a nova versão de seu texto, manuscrita, terminada. Nela, Sofia explica porque acha lindo o significado da música. Eu digo que acho ótima a explicação, pois dá um motivo pessoal e conecta com a tradução da letra que ela gosta. Sofia sorri novamente, se levanta, e diz que vai mostrar para a "Sora Sandra”. (Diário de Campo, 17/08/2011).

Nas nove instâncias similares a essa que estão registradas nos dados, podemos ver o engajamento de diversos alunos na reescrita de seus textos. Evidentemente, pode-se especular com alguma segurança que diversas outras semelhantes instâncias não foram registradas pelo pesquisador. Nesse excerto, pode-se ver o momento em que a aluna demonstra publicamente sua preocupação com os efeitos de sentido do seu texto na interação com o pesquisador. A aluna, após escrever o texto e recebê-lo bilhetado, engajou-se num processo de revisão e reescrita do texto, que começa na interação com o pesquisador, passa por pensar em como vai reescrever o texto, e culmina na reescrita da nota autobiográfica, bem como na busca por uma nova leitora para o seu texto. Além disso, é interessante sublinhar que esta aluna é a Sofia, a mesma retratada na nota anterior em que ela solicita ajuda para reescrever sua nota. Como dito, no início do processo, Sofia apresentava resistência ao engajamento, dizendo que não faria nada. Porém, isso foi modificando-se durante sua trajetória ao longo do projeto, culminando neste momento em que a aluna se engaja centralmente em uma atividade voltada à escrita. Há, nos dados, ao menos dois outros alunos cuja trajetória de engajamento é similar à de Sofia - de forte resistência a plena participação -, Matheus e Wellington.

Dessa forma, é possível relacionar a mudança na participação esboçada por esses participantes - Sofia, Matheus e Wellington - como evidências de aprendizagem, uma vez que partimos do pressuposto que participação e aprendizagem são faces do mesmo processo. 


\section{Quais formas de engajamento nas atividades de sala de aula sugerem o sucesso da empreitada?}

o projeto, como aponta o quadro sinótico de atividades apresentado anteriormente, prevê diversas tarefas de leitura, estudo do texto e trabalho com recursos linguísticos, todos orientados ao cerne da empreitada pedagógica: produzir uma nota autobiográfica para o $\mathrm{CD}$ da turma. A cada leitura correspondia um conjunto de tarefas de compreensão, estudo do texto e foco em recursos linguísticos centrais na constituição do texto em questão. Além disso, uma das aulas ocorreu na biblioteca; nesse encontro, os alunos foram apresentados a diversas antologias, posto que $\mathrm{o} C D$ da turma não deixasse de ser uma. Por fim, houve a parte central do projeto, isto é, aquela para qual todas as tarefas convergiam, a escrita das notas autobiográficas. Como já dito anteriormente, há nos diários de campo um grande número

"O som que faz a nossa cabeça" de segmentos que sugerem engajamento da turma. Isso, por si só, pode ser interpretado como uma aproximação dos alunos de práticas letradas a que os alunos não costumavam ter acesso, sequer na escola. De acordo com os alunos, eles liam pouco, alguns deles ainda não conheciam a biblioteca da escola, e não escreviam quase nunca, mesmo na escola.

Aqui nos interessa centralmente a escrita. Diversos trabalhos (historiados em Malfacini, 2015) apontam a natureza formalista do ensino de língua portuguesa: primeiro, no famigerado foco na gramática tradicional; mais recentemente, no foco em ensino de produção textual pautado na prescrição das características formais dos gêneros do discurso $^{19}$, isto é, ler para repetir. Propor a produção de textos escritos tanto como ponto de partida como de chegada é um modo de romper com um ensino focado na reprodução rumo a um ensino que ambiciona a produção de conhecimento. Isto se deve tanto por uma "opção ideológica de devolução do direito à palavra às classes desprivilegiadas, para delas ouvirmos a história contida e não contada da grande maioria" (Geraldi, 1997, p. 135), como pela percepção de que a escrita pode vir a ter um papel central nessa devolução da palavra.

Para discussão que segue, gostaríamos de retomar o percurso de Sofia. Como colocado anteriormente, Sofia foi uma aluna que apresentou resistência à participação no projeto, chegando a dizer que "não faria nada". Ao longo do percurso, foi-se apropriando da ideia de que poder dizer o que tem a dizer é, antes de um dever, um direito seu. Ao

19 Como bem explica o professor João Wanderley Geraldi em entrevista recente (Carivaldo et al., 2016). 
chegar aos encontros dedicados ao processo de planejamento, escrita e reescrita, Sofia já participava plenamente das atividades relacionadas ao projeto, tanto dentro como fora de sala de aula.

Como podemos ver nas figuras abaixo, a primeira e a segunda versão dos textos de Sofia são diferentes. Entre a primeira e a segunda versão, houve uma aula para reescrita dos textos, bilhetados pela professora da turma. NesWilliam se encontro, Sofia procurou a professora e o pesquisador para interagir sobre Kirsch o seu texto (relatado no excerto 3, apresentado anteriormente).

Simone

Sarmento

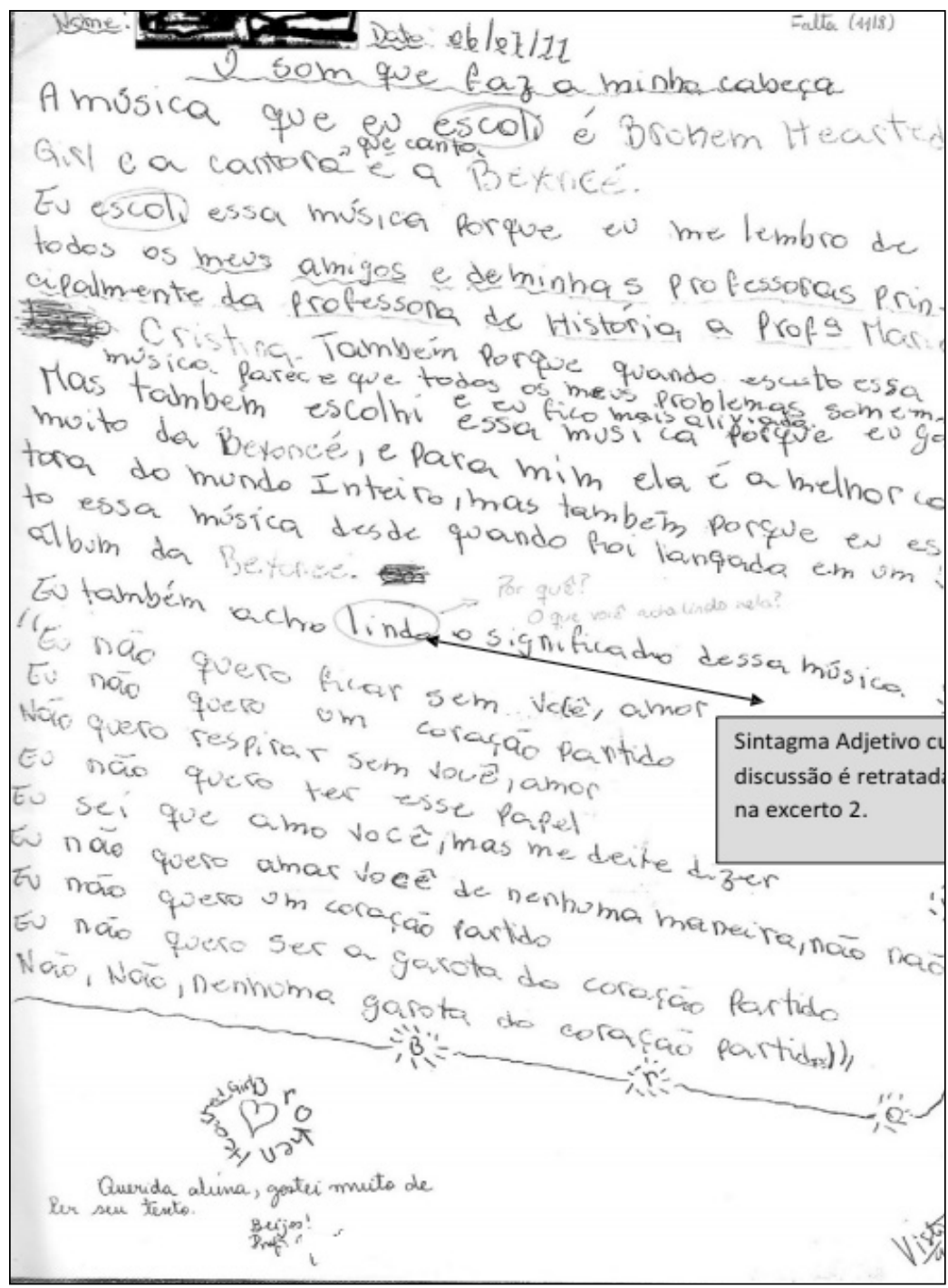

Imagem 1: texto diagnóstico de Sofia

Fonte: Autor (2012, p.113) 
O texto de Sofia apresenta uma série de aspectos lacunares em relação ao que queríamos alcançar com os textos finais a serem publicados no $C D$, alguns deles apontados nos bilhetes do pesquisador. Os aspectos que mais chamaram atenção foram: (1) a falta de divisão de parágrafos; (2) algumas questões de pontuação naquilo que parece ser o segundo parágrafo do texto; (3) ortografia. Por fim, há um sintagma adjetivo que, na leitura que fizemos, não explicava o porquê de Sofia gostar tanto da música para interlocutores que não fossem próximos o bastante para inferir o que é "lindo" desde a sua perspectiva. De modo que o bilhete solicita que Sofia explique por que ela acha a canção linda, caso veja isso como uma questão pertinente a ser endereçada em seu texto.

A segunda versão do texto de Sofia foi escrita em um período, na aula seguinte, quase sem assistência do pesquisador ou da professora, "O som que faz a nossa cabeça" exceto pela interação narrada na subseção anterior. Essa versão apresenta várias das questões levantadas resolvidas de modos que a consideramos satisfatória. Isso pode ser visto na figura abaixo:

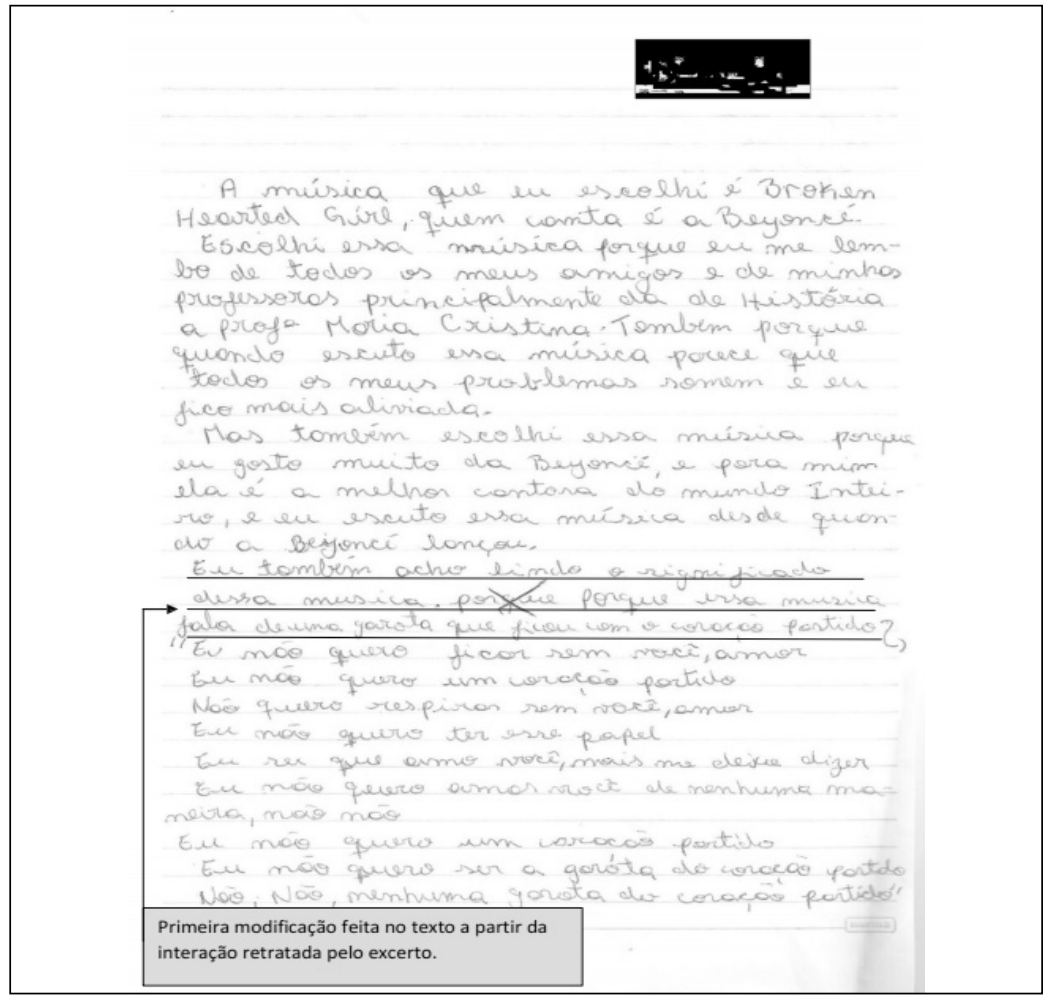

Imagem 2: versão final do texto de Sofia (antes da digitação)

Fonte: Autor (2012, p. 114) 
A segunda versão apresenta uma melhora no texto da aluna, na medida em que ela endereça as questões de linguagem levantadas pelos bilhetes de forma satisfatória. Além disso, a questão do sintagma adjetivo aparece resolvida de forma apropriada: a aluna reproduz a tradução de parte da canção, para mostrar exatamente o que é "lindo" em sua perspectiva. Ou seja, estava apropriada para ser publicada no CD da tur-

William ma, pois está adequada à proposta de escrita e ao gênero do discurso

Kirsch eleito e usa apropriadamente os recursos expressivos de que lança mão. É, portanto, um bom texto para os fins do projeto, deu a Sofia uma avaSimone liação quantitativa plenamente satisfatória e rendeu elogios de vários Sarmento leitores, o que é ainda mais destacado.

\section{Considerações finais}

Estimamos que este texto tenha apresentado satisfatoriamente um trabalho de pesquisa de dois anos - cujo relatório original é muito mais extenso e complexo - sem perder os elementos essenciais de sua construção e apresentando dados bastantes para que o leitor julgue por si as asserções analíticas com que o encerramos. Essas asserções constituem nada mais do que a generalização dos insights a que os dados empíricos nos conduziram a partir de nossos entendimentos e expectativas iniciais. Vamos às asserções:

1) O projeto foi uma experiência pedagógica bem-sucedida nos três índices de avaliação a que nossas lentes estiveram afinadas: (1) a participação dos alunos na construção do projeto; (2) o produto final - o próprio $C D$-, que evidencia um trabalho rico em aprendizagens por trás de sua construção; e (3) a melhoria das produções textuais dos alunos no decorrer do processo de escrita e reescrita. Desse modo, projetos didáticos, como os propostos aqui, podem ser de valor para a disciplina de língua portuguesa por fornecerem contextos concretos de uso da linguagem, em suas diversas modalidades, registros e facetas.

2) Nesse sentido, propiciar a criação de contextos reais e concretos para a escrita de textos que efetivamente alcancem interlocutores reais, concretos e interessados é (ou deve ser) um elemento básico de uma aula de língua portuguesa que se queira centrada no uso da linguagem. Como dito anteriormente, Geraldi já dizia isso em 1984, em seu livro, O Texto em Sala 
de Aula. No entanto, ainda hoje isso não passa de um projeto, um programa, uma utopia, talvez tão ou mais distante do que naquele longínquo ano.

3) Quanto mais concretos, interessantes e atraentes os suportes, e quanto mais interlocutores eles possam alcançar, maior a chance de que os alunos se tornem preocupados com a construção do texto, o que evidentemente tem o potencial de atingir o texto em suas mais variadas esferas composicionais - genéricas, linguísticas ou de outras naturezas materiais ${ }^{20}$.

Além disso, a visão de projetos didáticos para o ensino de língua delineada aqui tem sido desdobrada em outras produções dos autores, focadas no ensino de língua portuguesa (Autor, 2013) e no ensino de

"O som que faz a nossa cabeça" língua inglesa no ensino superior (Autor, 2014; 2018), bem como por outros professores e pesquisadores preocupados com o mesmo tema (Welp e Vial, 2016). Cumpre notar que as bases filosóficas acerca do ensino de língua propostas aqui tem-se mostrado promissoras nos contextos em que tem sido utilizadas para planejar o trabalho pedagógico. Porém, como assinalamos no início do texto, já eram indicadas há mais de trinta e cinco anos na obra de Wanderley Geraldi (1984).

\section{REFERÊNCIAS}

BAKHTIN, M. M. . Estética da Criação Verbal. São Paulo, Martins Fontes, 476 p., 2010.

BRASIL. Ministério da Educação, Secretaria de Educação Fundamental. Parâmetros Curriculares Nacionais: Primeiro e Segundos Ciclos do Ensino Fundamental: Língua Portuguesa. Brasília, MEC, SEF (PDF), 1998.

BRITTO, L. P. L. Escola , ensino de língua, letramento e conhecimento. Calidoscópio, 5(1), 24-30, 2007.

20 Após dar os textos por encerrados, prevemos apenas uma aula para "digitação" dos textos; descobrimos que os alunos queriam ainda trabalhar com seus textos em outros materiais que não os linguísticos - fonte, figuras, paginação, etc. Não apresentamos essas notas de campo e os textos finais por razão de espaço. 
ERICKSON, F. Qualitative Methods. In: R, LINN \& F, ERICKSON. Qualitative Methods, Quantitative Methods. London, Macmillan, p.77198, 1990.

FILIPOUSKI, A.M.; MARCHI, D.; SIMÕES, L. Referenciais Curriculares de Língua Portuguesa e Literatura do Estado do Rio Grande do Sul. Porto William Alegre, RS, Secretaria de Educação do Rio Grande do Sul, (PDF), 2009. Kirsch

Simone GERALDI, W. O texto na sala de aula: leitura e produção. Cascavel, AsSarmento 180

AUTOR, 2012.

AUTOR, 2013.

AUTOR, 2014

AUTOR, 2018.

LANGE, C. P. A Sala de Aula Contemporânea. BELT , 1(2), 99-105, 2010.

MALFACINI, A. C. S. 2015. Breve histórico do ensino de língua portuguesa no Brasil : da Reforma Pombalina ao uso de materiais didáticos apostilados. IDIOMA, 28, 45-59, 2015.

MASON, J. Qualitative researching. London, Sage, 1996.

MANGABeirA, A. B., costA, E. V. da, \& SimÕeS, L. J. O Bilhete Orientador : um gênero discursivo em favor da avaliação de textos na aula de Português. Cadernos Do IL, (42), 294-307, 2011.

MISHLER, E. Research Interviewing: context and narrative. Cambridge, MA, Harvard University Press, 1991.

OLIVEIRA, G. P. De. Avaliação Formativa Nos Cursos Superiores : Verificações Qualitativas No Processo De Ensino-Aprendizagem E 
a Autonomia Dos Educandos. Revista Iberoamericana de Educación, (April 2002), 1-6, 2007.

RAMPTON, B. Language in Late Modernity: Interaction in an Urban School. Cambridge, England, Cambridge University Press, 2006.

RODRIGUES, P. C. Concepção interacionista de ensino. F@pciência, 1(1), 1-10, 2007.

SCHLATTER, M.; GARCEZ, P. Referenciais Curriculares para o ensino "O som que faz a nossa de Língua Espanhola e Língua Inglesa. Porto Alegre, RS, Secretaria de cabeça" Educação do Rio Grande do Sul, 125-276 p. (PDF), 2009.

SCHNEWLY, B.; DOLZ J. Gêneros orais e escritos na escola. Campinas: Mercado de Letras, 2004. p. 95-128.

SIMÕES, L. J. et al. Leitura e autoria: planejamento em Língua Portuguesa e Literatura. Erechim: Edelbra, 2012.

WELP, A. K. S; VIAL, A. P. S. (2016). Currículo com Base em Projetos. Entrelinhas, 10(2), 230-255, 2016. 
